\title{
ANGKLUNG PIANO DENGAN PENGGERAK MOTOR ELEKTRIK
}

\author{
A.M. Susilo Pradoko, Panca Putri Rusdewanti, dan Fu'adi \\ Fakultas Bahasa dan Seni, Universitas Negeri Yogyakarta \\ E-mail: susilo_pradoko@uny.ac.id
}

\begin{abstract}
Abstrak
Penelitian ini bertujuan untuk memproduksi seperangkat alat musik angklung yang mampu merancang bangun sehingga teknik memainkan angklung tidak digoyang dengan tangan secara manual namun tinggal menyentuh seperti tuts piano. Angklung akan digoyang dengan penggerak baling-baling motor dinamo elektrik. Metode yang digunakan dalam penelitian ini menggunakan metode Research and Development dengan proses disesuaikan dengan karya musik dengan urutan sebagai berikut: pengumpulan data, desain produk, validasi desain, revisi desain, proses penciptaan karya seni, revisi penciptaan karya seni, uji coba pemakaian, pementasan angklung baling-baling motor elektrik dan publikasi. Rancangan hasil penelitian ini berupa: (1) menghasilkan satu produk angklung sistem piano dengan penggerak baling-baling motor elektrik.(2) mengahasilkan produk pengetahuan teknik rancang bangun penggabungan melodi dengan cukup disentuh seperti keyboard, dapat menghasilkan bunyi melodi dan trinada/akor; (3) Pada penelitian ini ada sebanyak 20 tut model piano yang mampu menggerkkan melodi angklung sebanyak 20 melodi angklung dari nada f' hingga nada c"'. Wilayah suara nada-nada melodi sebanyak 20 nada melodi ini mampu menyanyikan lagu-lagu, memberikan isian filler melodi maupun mengiringi akor dengan cara memainan tiga nada sekaligus; (4). Persiapan produk penelitian angklung sistem tuts piano dengan penggerak motor elektrik dapat di proses untuk mendapatkan HAKI.
\end{abstract}

Kata kunci: angklung, penggerak motor elektrik

\section{ANGKLUNG PIANO WITH ELECTRIC MOTOR PROPELLER}

\begin{abstract}
This research produces a set of angklung musical instruments with such a design so that the technique of playing angklung is not manually shaken by hand but just by touching it like a piano key. Angklung will be shaken using the drive of a dynamo electric motor propeller. The method used in this research was Reseach and Development study that has been adjusted to musical works in the following order: data collection, product design, design validation, artwork creation, artwork revision, artwork testing, Angklung electric motor propeller staging, and publication. The results of this research consist of: (1) producing one Angklung piano system with electrical motor propeller; (2) producing knowledge about designing technique of merging melody with touch like keyboard, can produce melodic and tune/chord sounds; (3) having 20 piano-modelled keys that can play 20 Angklung melodies from f' to c". These 20 melodic sound areas are able to sing some songs, provide filler melody entries or accompany chords by playing three tones at once; (4) processing the intellectual property rights for the Angklung piano system with electric motor propeller.
\end{abstract}

Keywords: Angklung piano system, electrical motor, intellectual property rights 


\section{PENDAHULUAN \\ Latar Belakang Pengembangan Instrumen Angklung}

Angklung telah ditetapkan sebagai warisan budaya tak benda (Intangible, Cultural Heritage of Humanity) oleh Organisasi pendidikan, Ilmu Pengetahuan, dan Kebudayaan (UNESCO) Peserikatan Bangsa-Bangsa (PBB) pada bulan November 2010. Sementara itu Duta Besar Indonesia untuk UNESCO menyatakan bahwa dalam waktu empat tahun bila Indonesia tidak bisa melestarikan serta mengembangkannya maka pengakuan warisan budaya tek benda tersebut bisa dicabut. (Kampas, 20 Januari 2011). Perguruan Tinggi memiliki tugas pengembangan Ilmu khususnya Angklung ini, sebab selama ini angklung belum banyak dikaji secara akademik melalui penelitian namun hanya dilestarikan dan dikembangkan melalui para pengrajin Angklung. Pengrajin angklung yang masih rutin berproduksi di Indonesia ini hanya dua kelompok yaitu Serambu Sumitro di Yogyakarta dan Saung Angklung Ujo. Pengembangan dalam bidang Ilmu dan teknologi Angklung tidak cukup hanya diserahkan pada dua sentra pengrajin tersebut karena keduanya tidak memiliki tradisi metodologi penelitian ilmiah. Andil Perguruan Tinggi dalam pengembangan angklung sangat perlu agar kurun 3 tahun lagi setelah diamati PBB tidak dijatuhkan sangsi pencabutan warisan budaya tak benda tersebut (Pradoko, 2014:1).

Indonesia miskin tenaga ahli yang memiliki kemampuan melakukan metode penelitian ilmiah tentang etnomusikologi angklung. Hal itu dikhawatirkan akan mempengaruhi pengembangan angklung dan statusnya sebagai warisan budaya tak benda dari Indonesia. Husein Hendriyana, Kepala Bidang Penelitian dan Pengabdian Masyarakat ISBI Bandung. menyatakan sebagai berikut: "Para pakar atau orang yang paham tentang angklung mungkin banyak. Tetapi yang mengerti metodologi penelitian ilmiah yang terstruktur saya rasa belum ada. Hal itu sangat ironis mengingat Indonesia merupakan negara asal angklung". (Kompas, 9 Februari 2011: 12). Universitas
Negeri Yogyakarta dapat merupakan salah satu pusat pengembangan akademik dalam bidang musik angklung karena secara nyata memang masih langka pakar metodologi ilmiah tentang angklung.

Angklung telah ditetapkan pula sebagai alat pendidikan musik sejak tanggal 23 Agustus 1968. melalui Keputusan Menteri Kebudayaan No.082/1968 tentang penetapan angklung sebagai alat pendidikan musik namun sampai saat ini pengembangan maupun penerapannya di sekolah-sekolah masih sangat minim (Winitasasmita dkk, 1978:5). Perhatian dunia perguruan tinggi memang masih sangat kurang hal ini disebabkan pula masih sangat jarang Perguruan Tinggi yang memberikan materi mata kuliah angklung sehingga aspek metodologis dan praksisnya dalam pertunjukan musik juga sulit berkembang. Selain itu peralatan angklung yang ditata memanjang dengan bentuk yang relative besar-besar untuk satu nada, sehingga memakan banyak tempat memerlukan kesulitan tersendiri dalam penyimpanan angklung di ruangan/kelas. Guru musik yang memiliki kemampuan teoritis musik angklung maupun metodologis dalam menyampaikan pembelajaran musik hingga pementasan juga sangat sedikit, karena pencantuman angklung sebagai materi mata kuliah baru dilakukan oleh UPI dan UNY, sebagai LPTK pendidik guru di sekolah-sekolah. Pembelajaran angklung dengan menggabungkan orchestra telah dirintis penulis sejak tahun 1996 dalam mara kuliah Musik Nusantara dan mata kuliah Etnomusikologi. Pengembangan angklung sangat minim di Indonesia ini baik dari sisi metodologi musikal, pembelajaran maupun pengembangan peralatan musik angklung untuk itulah maka Seni Musik FBS UNY terbeban untuk pengembangan musik angklung yang telah diakui UNESCO sebagai Intangible, Cultural Heritage of Humanity tersebut.

\section{Angklung Satu Nada Satu Pemain}

Angklung yang diajarkan selama ini masih berpola pada permainan satu nada dibunyikan oleh seorang pemain.Permainan model ini membutuhkan banyak orang 
untuk menghasilkan bunyi harmoni yang terpadu. Permainan model angklung seperti ini setidaknya memerlukan sekitar 15 orang pemain agar suaranya menjadi harmonis berdasarkan susunan nada-nada dan pemilihan teknik akor yang digunakan. Angklung satu nada-satu pemain cara menggerakkan dengan digoyang, tangan kiri diam memegang ancak angklung bagian atas sedangkan tangan kanan menggoyangkan ancak angklung bagian bawah. Pada penelitian ini seorang pemain dapat memainkan beberapa angklung melodi, akan dibuat satu set melodidengan sebanyak 18 angklung. Seorang pemain akan mampu memainkan sebanyak 18 nada-nada angklung.

\section{Angklung Melodi Tuts-tuts Piano dengan Sistem Penggerak Motor Elektrik}

Angklung telah diteliti dan dikembangkan dalam teknik permainannya oleh Pradoko dkk. Pengembangan angklung melalui metode research and development menghasilkan 4 rangkaian angklung, yaitu ranglaian sopran, alto, tenor dan bas. Cara memainkan angklung ini tinggal menyentuh dan menggertarkan tutstuts seperti memainkan piano. Pada sistem ini seorang pemain cukup menyentuh dengan jarinya tuts-tuts layaknya piano shingga dapat memainkan beberapa angklung sekaligus secara simultan beberapa nada angklung yang berarti dapat memainkan beberapa angklung sekaligus dalam satu waktu, detik dan durasi yang sama (Pradoko, 2015: 16). Pada penelitian sebelumnya, tuts-tuts papan piano angklung ditekan sambil digetarkan dengan tangan, pada penelitian ini penggerak getaran adalah motor elektrik yang menggerakan balingbaling, selanjutnya baling-baling menyentuh secara berulang bilah angklung sehingga menimbulkan goyangan dengan tenaga elektrik dan membunyikan nada angklung.

\section{Angklung Tradisional}

Musik angklung tradisional menggunakan tangga nada pentatonic slendro maupun pelok. Tangga nada slendro bila dikuasikan dengan tangga nada barat bunyinya seperti nadanada: c,d,e,g,a (do, re, mi, sol dan la) tangga nada seperti ini banyak di gunakan di wilayah Asia. Tangga nada pelog bunyinya seperti: e, f,g b,c (mi, fa, sol, si). Masing-masing daerah menggunakan nada-dasar sendiri-sendiri, tidak sama antar daerah yang satu dengan yang lain. Jaap Kunst menuliskan nada-nada angklung Banyuwangi sebagai berikut:

"The tunning of this instrument is-or, at any rate, tends to slendro, as is evident from the intervals of specimen in the musichological archives at Batavia, which originates from Banyuwangi:

$\begin{array}{llllll}298 & 350 & 414 & 457 & 544 & 596 \\ \text { I } 279 & \text { II } 290 & \text { III 172 } & \text { IV } 301 & \text { V 158 } & \text { I' }\end{array}$

(Kun, 1933: 198).

Pada halaman lain angklung slendro juga di daerah Tasikmalaya diungkapkan sebagai berikut: Scale of an angklung set from Tasikmalaya:

"174 $1961217 \quad 2471 / 228035592447504$ I II III IV V VI VII VIII IX” (Kun,1933: 362)

Dalam tangga nada diatonic Barat pitchnya tidak sama persis namun suara yang terdengar nada-nada angklung tersebut mirip dengan nada-nada ini:

$261^{1 / 2} \quad 293^{1 / 2} \quad 329^{1 / 2} \quad 392 \quad 440 \quad 523$

c' d' e' g' a' c'

Angklung tradisional dimiliki hampir seluruh wilayah di Indonesia hal ini karena materi bahan angklung yang terbuat dari bambu. Pohon bambu ada di hampir seluruh wilayah Indonesia dari Sabang sampai Merauke, bambu merupakan salah satu kekayaan alam Indonesia terdapat 60 jenis bambu di Indonesia ini. Bambu sering dimanfaatkan menjadi berbagai alat untuk kebutuhan hidup mulai dari rumah tinggal, peralatan dapur hingga kebutuhan sosial dan seni bahkan untuk dimakan, bambu yang masih muda.

Angklung ada di berbagai daerah di Indonesia seperti yang dipaparkan Jaap Kunst berikut ini: 
"In recent times, however, it is still reported as having been seen in the territory of Banyumas, Cirebon, Brebes, Purbalingga, Wanasaba, Bagelen, Yogya, Solo; in the regencies Panaraga, Trenggalek, Tulungagung, Majakerta, Sidaarja, Grisee, Surabaya, and Purbalingga; as well as in Madura, Bali, South Sumatra and S.W. Borneo, ..." (Kunst, 1948: 361).

Aransemen dalam musik tradisi masih sangat sederhana, aransemen musik dalam permainan hanya membunyikan nada-nada yang sama tetapi dengan instrument yang bersuara lebih rendah (alat-alat basnya) atau lebih tinggi satu oktaf. Variasi ritmik yang diperbanyak antar angklung yang satu dengan yang lain, misalnya ada yang mebunyikan pada beatnya, per satu ketukan ada yang membunyikan setiap setengah ketukan atau bahkan sepermepat ketukan sehingga musiknya menjadi meriah walaupun kekayaan nadanya kurang karena hanya lima nada, pentatonik.

\section{Angklung Diatonik}

Angklung ini disebut Angklung diatonik karena nada-nadanya disesuaikan dengan skala nada diatonic yaitu do, re, mi, fa, sol, la, si do, jadi tidak berskala nada Pentatonik (da-mi-na-ti-la-da) seperti pada angklung tradisional. Angklung Diatonik ini biasa juga disebut Angklung Padaeng karena Daeng Soetigna yang pertama kali membuat dan memperkembangkannya. Daeng Soetigna, seorang guru HIS pada zaman kolonial Belanda di Kabupaten Kuningan Jawa Barat yang telah mengangkat derajat angklung di tengah masyarakat. Pada tahun 1938, sebagai seorang yang telah mendapat pendidikan Barat, namun tidak terasing dengan lingkungan hidupnya, telah diusahakan agar angklung daerah yang berskala nada pentatonic, yang telah member kegembiraan pada masa kecilnya diubah menjadi skala nada Diatonik dengan dibantu Bapak Jaya yang terbiasa membuat angklung daerah (Angklung Sunda), Pak Daeng telah berhasil membuat 1 set angklung Diatonik Angklung Diatonik dikembangkan oleh Daeng Soetigna pada tahun 1938. Angklung di daerah sunda dan di beberapa di tanah air sebelumnya penalaannya menggunakan tangga nada pentatonik. Angklung diatonic yang telah dibuat ini kemudian digunakan oleh Bapak Daeng untuk mengajar anak-anak Pramuka. Sejak saat itulah maka angklung model diatonik berkembang sampai sekarang (Winitasasmita, 1978: 14).

Angklung diatonik telah ada di Museum Auckland sejak tahun 1930, Angela B. Annabel menuliskan angklung diatonik yang ada di Aukland dengan perbandingan Tangga nada pentatonik pelog yang dikemukakan Jaap Kunst sebagai berikut:

"Nearest equivalent notes of the European scale are given below frequency numbers. It will be seen that whrer comparison is possible differences in terms of vibration frequencies and cent-intervals are only slight. Comparison of a West Javanese pelog scale (Kunst, 1973:2) with sound measurements obtained from angklung in the Auckland Museum.

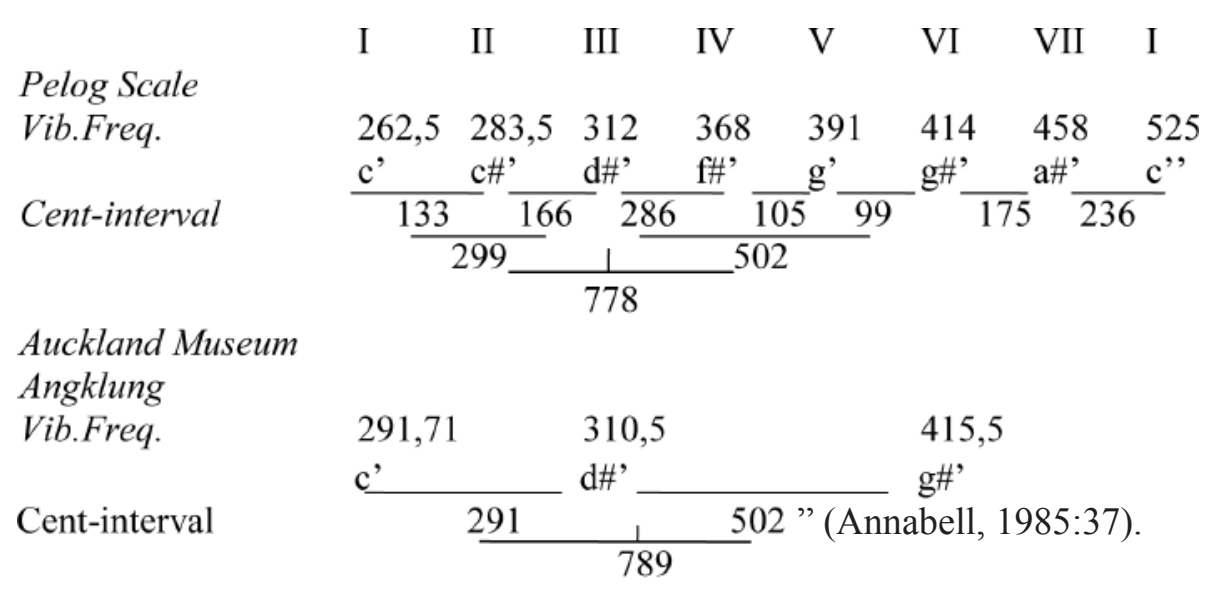


Annabel mengungkapkan bahwa angklung yang menjadi koleksi di Museum Auckland memiliki sistem tannga nada dengan frekwensi sistem cent-interval persis (nearest) sistem Eropa. Inilah merupakan keuntungan angklung diatonic Pak Daeng, karenanya pula maka sisi penggarapan organisasi musikalnya juga akan bisa dibuat model harmoni orchestra Eropa.

Permaianan angklung menurut Arnold B.Perris dalam artikelnya The Rebirth of the Javanese Angklung menuliskan sebagai berikut:

"Each angklung player hols an instrument in one hand, and shake it with the other hand. A melody is performed by providing as many angklung and players as required by different pitches of the tune, much the west. And in a similar technique, multiple tones may be sounded, yielding a second or third part, including chords. The sizes range from three inches to three feet. In an experienced chords, especially a small group, each player may play two instruments sliding one up his forearm " (Perris, 1985:37).

Angklung melodi maupun akor dimainkan oleh banyak orang dan seorang pemain hanya memegang maksimal dua nada aklung akor atau dua angklung melodi.

Model memainkan angklung yang sederhana, biasanya dilakukan di tingkat SD dan SMP dimainkan dengan cara sebagian anak memegang angklung melodi dan sebagian lagi memegang angklung akor, melodi lagunya diiringi angklung akor-akor. Model bermain lain dengan cara memainkan score notasi paduan suara, dari score notasi tersebut kemudian dibagi-bagi not-not yang tertera dalam angklung dengan nada-nada yang sesuai, satu orang memegang satu atau dua nada angklung melodi atau akor. Winitasasmita dan Budiman mengungkapkan cara membuyikan angklung melodi maupun angklung akor dengan cara sebagai berikut:

“... Adapun cara membunyikan angklung ialah sebagai berikut: (1) tangan kiri jangan ikut bergerak tetapi harus tetap diam, (2) angklung harus diusahakan tetap tergantung tegak lurus, (3) tangan kanan (pergelangannya) digerakkan kea rah kiri dan kanan berulang-ulang. Makin cepat menggerakkan makin baik, juga tak usah terlalu keras agar suara yang ditimbulkan terdengar halus" (Winitasasmita dan Budiman, 1978:29).

Setelah angklung di bagi-bagi kepada para pemain, selanjutnya para pemain memainkan not-not melodi yang dibaca sesuai dengan nada dan durasi lamanya nada dibunyikan.

Angklung adalah instrumen musik tradisional yang termasuk dalam keluarga instrumen Perkusi. Dikatakan demikian, karena jika dilihat dari sumber bunyi yang dihasilkan, berasal dari Angklung itu sendiri.Dalam ilmu organologi, hal ini disebut dengan Idiophone, yaitu sumber bunyinya berasal dari tubuh instrumen itu sendiri. Pernyataan tersebut seperti diutarakan oleh Hosch (1988:215) bahwa instrumen idiophone adalah instrumen yang sumber bunyinya berasal dari instrument itu sendiri.

Pada dasarnya, instrumen Angklung sangat mudah untuk dimainkan. Namun, untuk memainkan dengan baik diperlukan teknikteknik permainan yang baik dan benar. Terdapat tiga teknik permainan dalam instrumen Angklung (Kebudayaan Indonesia,2014:4), yaitu Kurulung (getar), Cetok (sentak), dan Tengkep. Secara rinci ketiga teknik tersebut diuraikan sebagai berikut.

1. Kurulung merupakan teknik yang paling umum dipakai, di mana satu tangan memegang rangka angklung, dan tangan lainnya menggoyangkan angklung selama nada yang diinginkan, hingga tabungtabung bambu yang ada silih beradu dan menghasilkan bunyi.

2. Cetok (sentak) yakni teknik di mana tabung dasar ditarik dengan cepat oleh jari ke telapak tangan kanan, sehingga angklung akan berbunyi sekali saja (staccato).

3. Tangkep, yakni teknik yang mirip seperti kurulung, namun salah satu tabung ditahan tidak ikut bergetar. 


\section{Pengembangan Permainan Angklung Sistem} Piano

A.M. Susilo Pradoko, dkk. meneliti tentang teknik permaianan angklung dengan model sistem piano, teknik ini memungkinkan seorang pemain membunyikan angklung lebih dari satu nada melodi maupun satu akor. Teknik ini dengan menjajar angklung dan diberi tambahan mekanik tuts-tuts dan papan nada serta pantulan karet sehingga cara membunyikan tinggal di sentuh seperti memainkan piano. Dalam penelitianannya Pradoko dkk.mengungkapkan sebagai berikut:

"Setelah mengumpulkan data dan bahan-bahan objek materi guna pembuatan angklung model SATB Sistem Piano selanjutnya mendesain produk dengan model rak untuk masingmasing suara angklung Sopran, Alto, Tenor dan Bas. Selanjutnya dibuat ketepatan tempat masing-masing angklung. Revisi desain dilakukan dengan memperpendek rak masingmasing angklung yang semula dalam posisi pemain berdiri dibuat menjadi pemain duduk. Proses pembuatan dengan dibuat tuts-tuts dan perluasan pemukul dan mengkaitkan angklung dengan dua karet pemantul depan dan belakang. Ketika karet pemantul dua bagian depan dan belakang ternyata untuk menghasilkan bunyi maka tuts-tuts perlu ditekan dengan berat. Revisi produk angklung SATB-SP dirubah dengan pemasangan karet pantul hanya bagian ancak angklung dan hasilnya penekanan tutstuts angklung lebih ringan" (Pradoko dkk, 2014: 12).

\section{Cara Kerja Motor Elektrik Penggerak Kipas Angin}

Pada umumnya cara kerja kipas angin ada pada pemutar kipas angin yang digerakkan oleh motor listrik. Prinsip kerja yang digunakan adalah mengubah energi listrik menjadi energji grak. Dalam sebuah motor listrik terdapat sebuah kumparan besi pada bagian yang bergerak Gaya tolak-menolak pada kutub magnet membuat membuat gaya berputar secara periodik (Destroy, Laporan Praktek Elektronika Politeknik Negeri Sriwijaya, melalui http:www.
academia.edu.Cara Kerja Kipas Angin). Gerak putar motor elektrik ini kemudian diberi baling-baling kipas, sehingga kipas menjadi ikut berputar pula. Kipas yang berputar dengan gerak kekuatan tertentu sesuai kekutan motor dimanfaatkan guna menggerakkan angklung sehingga angklung menjadi mampu bergoyang secara dengan tenaga listrik.

\section{PEMBAHASAN}

Rancang Bangun Musik Angklung Tuts Piano Pengerak Motor Elektrik

\section{Model Angklung SATB SP}

Angklung electone yang akan diproduksi mengkombinasikan gagasan pembuatan angklung SATB SP yang dibuat oleh A,M, Susilo Pradoko dkk, terutama penggunaan sistem tuts-tuts, atau bilah-bilah nada untuk melodi sopran seperti teknik permainan piano. Sistem bilah nada tersebut adalah sebagai berikut:
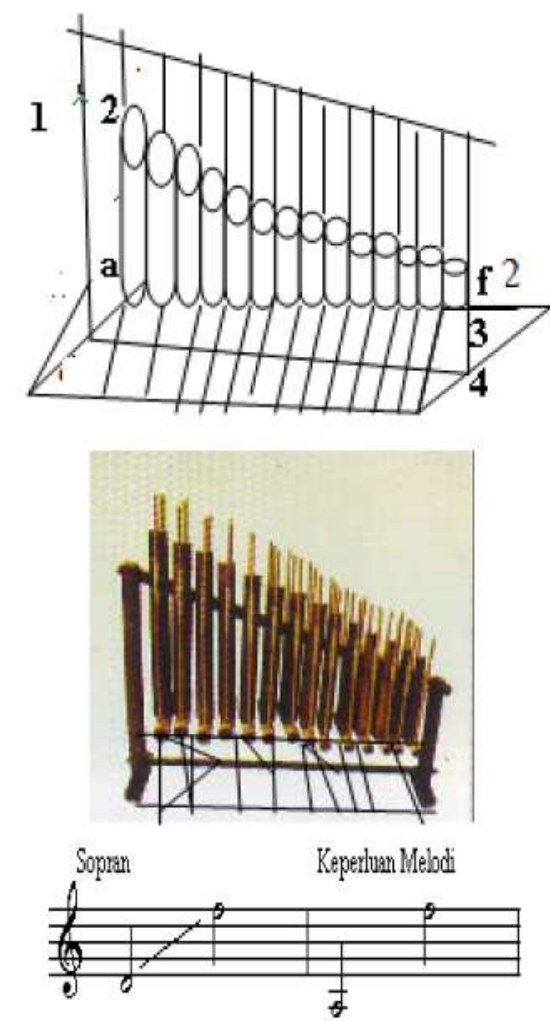

Keterangan:

1. Kerangka Angklung

2. Tabung-tabung Angklung Nada-nada Wilayah melodi: Terdiri dari nada-nada dari a s/d f2 yaitu nada-nada: a1, ais1, b1, c2, cis2, d2, dis2,e2,f2, fis2, g2, gis2, a2, ais2, b2, c3, cis3, 
d3 Terdiri dari 18 tabung nada dan masing-masing nada ada dua tabung melodi agar ada penguat suara nada pokok; sehingga ada 36 tabung nada-nada melodi.

3. Pantulan karet kanan.

4. Pantulan Karet kiri.

\section{Desain Penggerak Baling-baling Motor Elektrik Penyentuh Angklung}

Dinamo motor elektrik yang terjadi karena saling tarik menarik medan magnit mengerakan perputaran batang as besi. Batang as besi ini kemudian diberi baling-baling kipas, sehingga kipas menjadi ikut berputar pula. Kipas yang berputar dengan gerak kekuatan tertentu sesuai kekutan motor dimanfaatkan guna menggerakkan angklung sehingga angklung menjadi mampu bergoyang secara dengan tenaga listrik. Desain perputaran baling-baling yang menggerakan angklung digambarkan sebagai berikut ini:

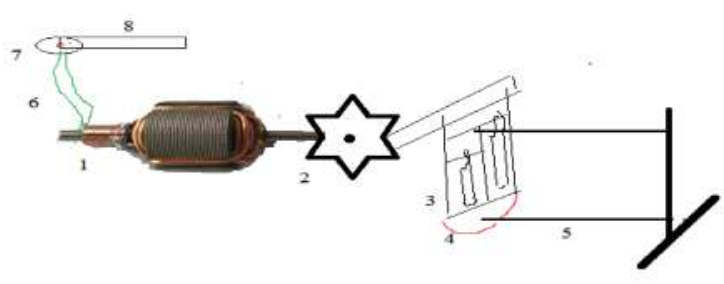

Keterangan:

1. Baling-baling kipas

2. Ancak angklung melodi dua tabung

3. Karet pemantul kembali

4. Rak tempat-tempat angklung

5. Kabel penghubung listrik

6. Tombol on off listrik

7. Tuts penekan sistem piano

(Dinamo motor penggerak angklung, Pradoko, 28/3-17)

Langkah kerja terjadinya dinamo motor elektrik untuk menggerakan angklung sebagai berikut:

Pertama papan tuts (no:8) saat ditekan maka akan menyentuh tombol elektrik (7), tombol elektrik kemudian mengalirkan listrik melalui kabel (6) ke dinamo (1), batang dalam dinamo berputar, karena baling-baling (2) rekat dengan batang dinamo maka turut berputar pula. Baling-baling (2) yang berputar selanjutnya menyentuh tuts ancak angklung (3). Ancak angklung akan bergerak ke bawah, namun karena ada karet pemantul (4), maka tuts angklung akan kembali pada posisi semula, saat kembali pada posisi semula, ditekan lagi oleh baing-baling demikian seterusnya sehingga terjadi goyangan tenaga elektrik menjadi tenaga mekanik. Goyangan-goyangan yang bertubi-tubi inilah yang akhirnya menggantikan goyangan manual tangan manusia, demikian terjadilah bunyi musik angkung. Saat aliran listrik pada tombol (7) tidak ditekan maka tidak ada aliran listrik sehingga tekanan mekanik untuk menggerakan angklung otomatis juga berhenti, kipas baling-baling tak lagi kuat untuk menggerakan ancak angklung dengan dua tabung melodi.

\section{Desain Produk dan Revisi Desain}

\section{Desain Awal Piano Motor Elektrik}

Desain awal perputaran baling-baling yang menggerakan angklung digambarkan sebagai berikut ini:

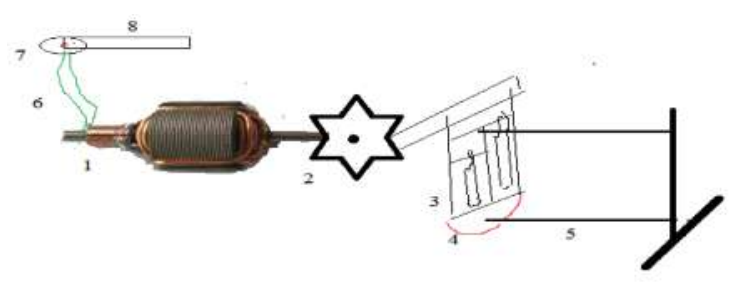

Keterangan:

1. Baling-baling kipas

2. Ancak angklung melodi dua tabung

3. Karet pemantul kembali

4. Rak tempat-tempat angklung

5. Kabel penghubung listrik

6. Tombol on off listrik

7. Tuts penekan sistem piano

(Dinamo motor penggerak angklung, Pradoko, 28/3-17)

Langkah kerja terjadinya dinamo motor elektrik untuk menggerakan angklung sebagai berikut:

Pertama papan tuts (no: 8) saat ditekan maka akan menyentuh tombol elektrik (7), tombol elektrik kemudian mengalirkan listrik melalui kabel (6) ke dinamo (1), batang dalam dinamo berputar, karena baling-baling (2) rekat dengan batang dinamo maka turut berputar pula. Baling-baling (2) yang berputar selanjutnya menyentuh tuts ancak angklung (3). Ancak angklung akan bergerak ke bawah, namun karena ada karet pemantul (4), maka tuts angklung akan kembali pada posisi semula, saat 
kembali pada posisi semula, ditekan lagi oleh baing-baling demikian seterusnya sehingga terjadi goyangan tenaga elektrik menjadi tenaga mekanik. Goyangan-goyangan yang bertubi-tubi inilah yang akhirnya menggantikan goyangan manual tangan manusia, demikian terjadilah bunyi musik angkung.

Pada saat dilaksanakan desain ini, ternyata dinamo elektrik berkekuatan 12 volt tidak kuat mennggerakkan angklung ini. Pada saat baling-baling diberi aliran listrik kemudian menyentuh bambu angklung ternyata tidak kuat, selanjutnya dibuat dengan sistem getaran. Dengan memanfaatkan sistem getarannya dinamo dengan kekuatan 12 volt mampu menggerakkan angklung maluai dari angklung nada f' hingga nada c"”.

\section{Revisi Desain Penggerak Angklung Motor Elektrik}

Motor 12 volt dengan baling-baling ternyata tidak mampu mennggarakkan angklung, selanjutnya didesain dengan pemanfaatan getaran motor elektrik. Getaran motor elektrik diperoleh dengan memberikan penggaris dilekatkan dengan putaran motor. Selanjutnya penggaris diberi beban salah satu ujungnya dengan baut, pembebannan salah satu ujung penggaris ini dimaksudkan agar ada efek beban goyang yang berbeda antara ujung kiri dan kanan penggaris. Efek beban yang berputar ini menghasilkan kekuatan getaran yang berlebih disbanding tidak diberikan bandul salah satu ujung penggaris.Efek getaran bandul baut yang berputar karena penggarisnya berputar inilah yang dimanfaatkan untuk mennggetarkan angklung.

Pada saat tuts papan piano ditekan, tombol listrik tertekan maka mengaliri arus listrik. Saat alur listrik mengalir motor berputar dan menggerkkan bandul baut yang terdapat di penggaris salah satu ujungnya, efek getar bandul penggaris yang tidak imbang ujung kiri dan kanan inilah yang akhirnya mampu mengetarkan alat musik angklung. Pada penelitian ini ada sebanyak 20 tut model piano yang mampu menggerkkan melodi angklung sebanyak 20 melodi angklung dari nada f' hingga nada c"'. Wilayah suara nada-nada melodi sebanyak 20 nada melodi ini mampu menyanyikan lagu-lagu, memberikan isian filler melodi maupun mengiringi akor dengan cara memainan tiga nada sekaligus. Gambar revisi desain serta keterangannya dipaparkan berikut ini:

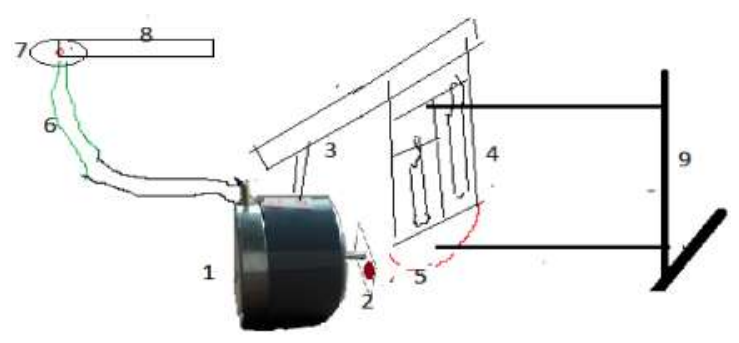

Keterangan:

1. Motor elektrik

2. Baling-baling dengan beban

3. Perpanjangan penggoyang angklung

4. Ancak Angklung

5. Kabel listrik

6. Tuts tombol on/off listrik

7. Papan tuts model piano

8. Rak tempat angklung

Dengan memanfaatkan sistem getarannya dinamo dengan kekuatan 12 volt mampu menggerakkan angklung maluai dari angklung nada $f$ ' hingga nada c"”, baling-baling tidak menyentuh langsung angklungnya namun gerekkan bergetar ini yang dimanfaatkan untuk mennggerakkan angklung-angklung melodi.

\section{Hasil Produksi Angklung Piano Penggerak Motor Elektrik}

Produksi angklung piano penggerak motor elektrik ini telah diuji coba ikut berpartisipasi guna iringan ketoprak gejog lesung dan angklung. Partisipasi mengiringi ketoprak Gejog Lesung dan Angklung ini dilaksanakan di Halaman Parkir Candi Kalasan pada tanggal 7 Oktober 2017. Angklung Piano penggerak motor elektrik ini setelah mampu dimainkan seluruh nada-nadanya kemudian dikemas dalam bentuk alat musik dan diberi kotak box sehingga mudah dibawa-bawa dan rapi, hasil produk setelah diberikan kotak box sebagai berikut ini. 


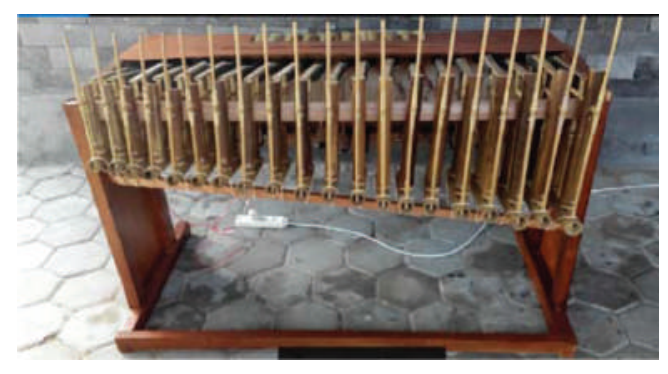

Produk angklung piano penggerak motor elektrik

(dokumentasi Pradoko: 3 Oktober 2017)



Tampak samping angklung piano motor elektrik

(dokumentasi Pradoko: 3 Oktober 2017)

Foto pemanfaatan hasil karya dalam pementasan iringan Ketoprak Gejog Lesung dan Angklung sebagai berikut ini:

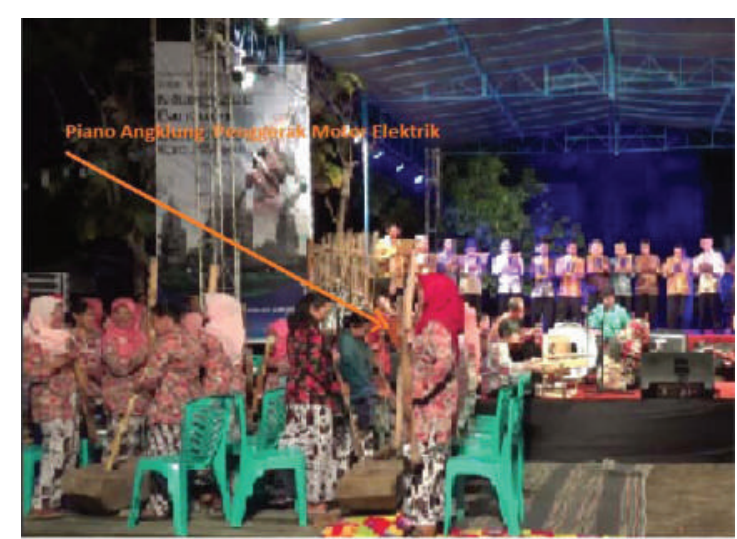

Piano Motor Elektrik digunakan untuk pentas ketoprak gejog lesung angklung pada 7 Oktober 2017

\section{KESIMPULAN}

Rancangan hasil penelitian ini berupa: (1) menghasilkan satu produk angklung sistem piano dengan penggerak baling-baling motor elektrik. (2) menghasilkan produk pengetahuan teknik rancang bangun penggabungan melodi dengan cukup disentuh layaknya keyboard, dapat menghasilkan bunyi melodi dan trinada/ akor; pada penelitian ini ada sebanyak 20 tut model piano yang mampu menggerkkan melodi angklung sebanyak 20 melodi angklung dari nada f' hingga nada c"'. Wilayah suara nada-nada melodi sebanyak 20 nada melodi ini mampu menyanyikan lagu-lagu, memberikan isian filler melodi maupun mengiringi akor dengan cara memainan tiga nada sekaligus; (3) persiapan produk angklung sistem tuts pianodengan penggerak motor elektrik dapat di proses untuk mendapatkan HAKI.

\section{DAFTAR PUSTAKA}

Annisa Pratiwi. 2013. Pelestarian Angklung Sebagai Warisan Budaya Takbenda dalam Pariwisata berkelanjutan di Saung Angklung Udjo, Bandung. Denpasar: Thesis Program Pascasarjana Universitas Udayana.

Destroy. 2017. Kipas Angin-Cara Kerja Kipas Angin. Diunduh dari: http://www. Academia.edu.

Rochmad.2012." Desain Model Pengembangan Perangkat Pembelajaran Matematika" dalam Kreano. Semarang: Jurusan Matematika MIPA UNNES.

Kawakami, Genichi. 1975. Arranging Popular Music. Tokyo: Yamaha Music Foundation. Kompas. 2011. "Pengakuan Warisan Budaya Bisa Dicabut" Jakarta: Kompas, 20-1-2011.

2011. "Tenaga Ahli Angklung Masih Sangat Terbatas" Jakarta: Kompas, $\operatorname{tg} 1$ 9-2-2011

Korsakov, Nikolay Rimsky. 1964. Principles of Orchetration. New York: Dover Publication

Pradoko, A.M. Susilo, dkk. 2014. Rancang Bangun Musik Angklung Model SATB, Dasar Aransemen Model Orchestra. 
127 imasi, Vol. 16, No. 2, Oktober 2018: 118 - 127

Yogyakarta: Laporan Hasil Penciptaan Karya Seni, Fakultas Bahasa dan Seni Universitas Negeri Yogyakarta. . 2016. Rancang Bangun Musik Angklung Model Electone Organ Perpaduan Kombinasi Bas, Harmoni dan Melodi. Yogyakarta: Laporan Penciptaan Karya Seni

Supriyadi. 2006. "Calung dan Cara Pembuatannya”. Dalam Selonding Vol.IV. No. 2. Sept. 2006. Yogyakarta: Jurusan Etnomusikologi ISI.

Winisasmita, Moh. Hidayat dan Budiaman. 1978. Angklung Petunjuk Praktis. Jakarta: Balai Pustaka.

\section{Jurnal Internasional}

Annabel, Angela R. 1985. "Javanese Angklung in The Auckland Institute and Museum". Records of The Auckland Institute and Museum. Vol. 22. http://www.jstor.org/ stable/42906347. Pp. 31-40.

Perris Arnold B. 1971. "The Rebirth of The Javanese Angklung" dalam Ethnomusicology Vol. 15. No. 3 Sep.1971. http://www.jstor.org/stable/85064. pp.403407. 